\title{
Unusual presentation of Lisfranc fracture dislocation associated with high-velocity sledding injury: a case report and review of the literature
}

\author{
Christopher E Benejam*1 and Steven G Potaczek²
}

Address: ${ }^{1}$ Augustana College, 38th Street, Rock Island, IL, 61201, USA and 2Department of Orthopedic Surgery, Galesburg Clinic, N Seminary St, Galesburg, IL, 61401, USA

Email: Christopher E Benejam* - cbombligo@gmail.com; Steven G Potaczek - sgpmd@ hotmail.com

* Corresponding author

Published: II August 2008

Journal of Medical Case Reports 2008, 2:266

doi:10.1186/1752-1947-2-266

Received: 24 December 2007

Accepted: II August 2008

This article is available from: http://www.jmedicalcasereports.com/content/2/I/266

(C) 2008 Benejam and Potaczek; licensee BioMed Central Ltd.

This is an Open Access article distributed under the terms of the Creative Commons Attribution License (http://creativecommons.org/licenses/by/2.0), which permits unrestricted use, distribution, and reproduction in any medium, provided the original work is properly cited.

\begin{abstract}
Introduction: Lisfranc fracture dislocations of the foot are rare injuries. A recent literature search revealed no reported cases of injury to the tarsometatarsal (Lisfranc) joint associated with sledding.

Case presentation: A 19-year-old male college student presented to the emergency department with a Lisfranc fracture dislocation of the foot as a result of a high-velocity sledding injury. The patient underwent an immediate open reduction and internal fixation.

Conclusion: Lisfranc injuries are often caused by high-velocity, high-energy traumas. Careful examination and thorough testing are required to identify the injury properly. Computed tomography imaging is often recommended to aid in diagnosis. Treatment of severe cases may require immediate open reduction and internal fixation, especially if the risk of compartment syndrome is present, followed by a period of immobilization. Complete recovery may take up to I year.
\end{abstract}

\section{Introduction}

An unusual case of Lisfranc fracture dislocation of the foot resulting from a high-velocity sledding injury is discussed. A recent literature search revealed no reported cases of injury to the tarsometatarsal (Lisfranc) joint associated with sledding.

\section{Case presentation}

A healthy 19-year-old male college student presented to the emergency department with acute pain in the left foot after sustaining a sledding injury. While sledding in the sitting position and with legs extended, the plantar aspect of his left foot struck a tree limb at high speed. The pain was throbbing and did not radiate. Weight bearing was impossible. Previous medical and surgical records were unremarkable.

On physical examination, localized swelling and tenderness of the dorsal aspect of the midfoot prevented weightbearing or movement of the foot and ankle. Circulation and neurological examinations were normal. The skin was intact.

Foot radiograph demonstrated a Lisfranc fracture dislocation (Fig. 1). A subsequent CT scan is shown (Fig. 2).

This patient underwent an immediate open reduction and internal fixation of the Lisfranc fracture-dislocation. A 


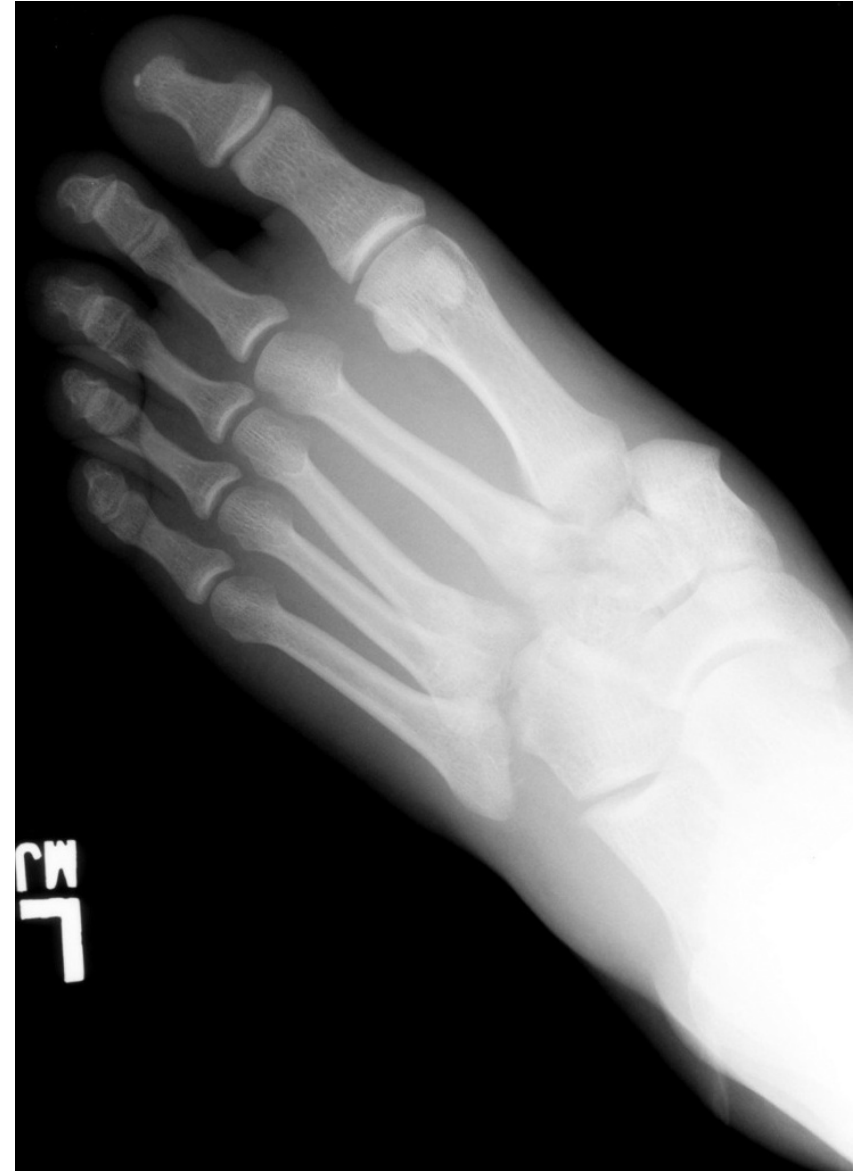

Figure I

Radiograph of the left foot. There is lateral displacement of the first, second, and third metatarsals (tarsometatarsal or Lisfranc joint) with associated fracture of the middle cuneiform.

postoperative radiograph is shown (Fig. 3). He was treated with a non-weight-bearing cast followed by a weight-bearing boot. He was advised to refrain from strenuous physical activity for 6 weeks after removal of the boot, after which time, normal physical activity was resumed. A nonsteroidal anti-inflammatory drug was prescribed for pain. The patient had only mild pain with weight-bearing at 6 months and was ambulating without difficulty; he was pain-free at 2 years.

\section{Discussion}

The Lisfranc joint derives its name from Jacques Lisfranc (1790-1847), a surgeon in Napoleon's army. Lisfranc performed amputations through the tarsometatarsal (TMT) joint to treat gangrenous injury of the foot [1]. Injuries of the Lisfranc joint are rare, representing less than $0.2 \%$ of all orthopedic traumas [2]. However, as many as $20 \%$ of Lisfranc joint injuries are missed upon initial examination [3]. The injury should always be suspected following

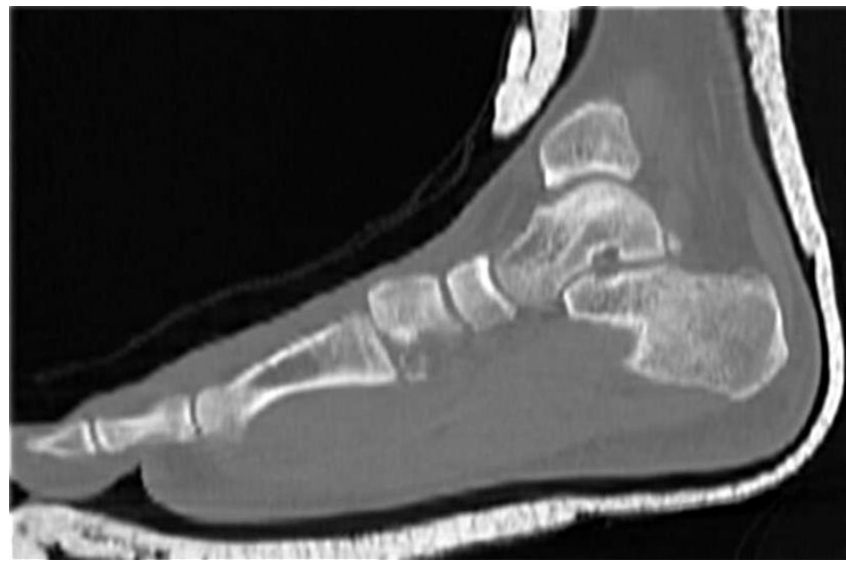

Figure 2

Computed tomography of the left foot. There is disruption of the tarsometatarsal (Lisfranc) joint with associated soft tissue swelling.

trauma to the foot [4]. Most commonly, Lisfranc joint sprains and fractures are caused by high-velocity traumas, such as motor vehicle and industrial accidents. Injuries can be sustained during many athletic activities. In this case, injury was caused by direct impact of the foot against a tree trunk resulting in acute plantar flexion. In patients with high-energy trauma foot injury, CT imaging is often recommended to aid in diagnosis [5].

Mild sprains to the Lisfranc joint, where there is no evidence of diastasis, may be treated by immobilization [6]. Treatment of more severe cases such as dislocations, however, usually includes open reduction and internal fixation of the joint. Cortical screw fixation is preferred to Kirschner wire fixation for these injuries [7]. The joint is secured to reduce without diastasis the lateral border of the medial cuneiform to the second metatarsal [3]. Surgery may be postponed to allow for reduction in tissue edema. However, if a risk of compartment syndrome is present, surgery should be performed immediately. After surgery, the foot is immobilized in a non-weight-bearing cast for 6 to 8 weeks, after which, the foot may be placed in an immobilizing boot with minimal weight bearing. After an additional 6 to 8 weeks, the boot may be removed and full weight-bearing may be established gradually. Complete recovery often takes up to 1 year [3], although long-term disability is possible. Despite appropriate reduction and fixation, patients may develop chronic post-traumatic arthritis [8]. Primary complete arthrodesis as a salvage procedure [9] is recommended only for severe chronic pain.

\section{Conclusion}

Lisfranc injuries are often caused by high-velocity traumas. Careful examination and thorough testing are 


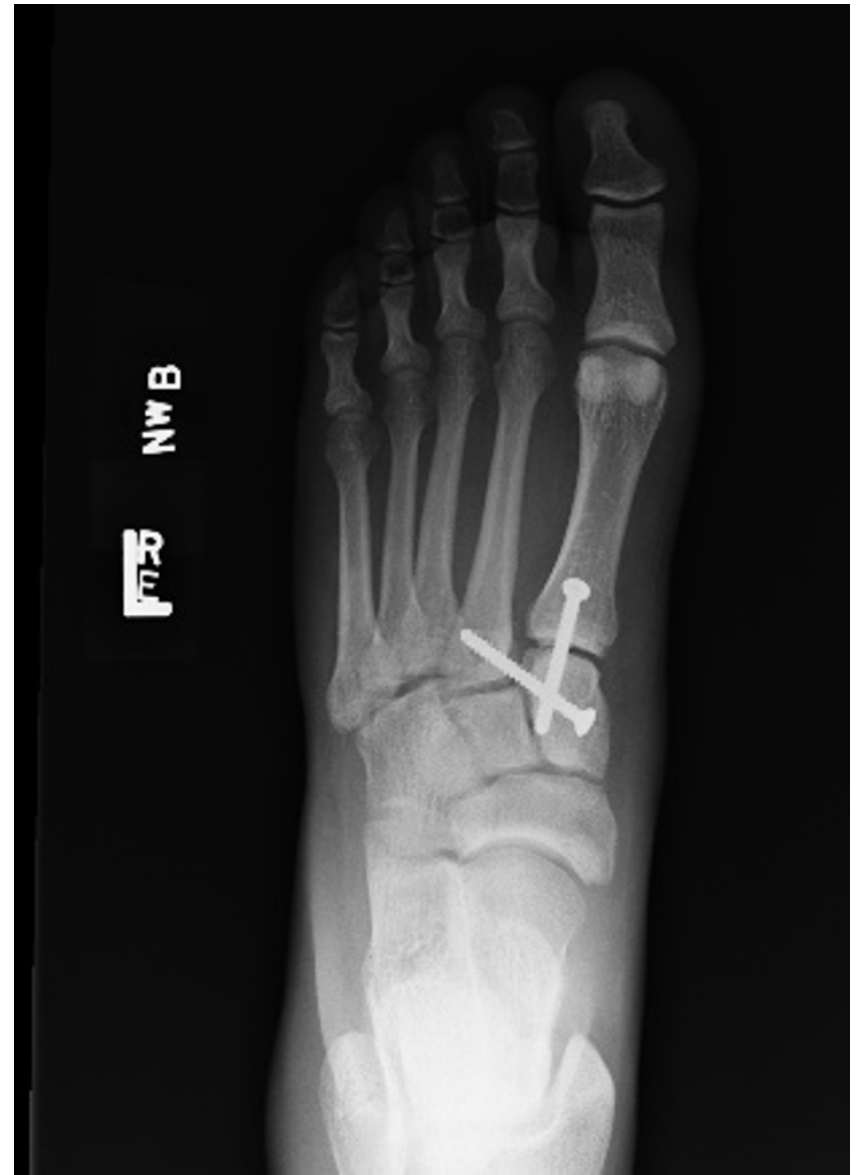

Figure 3

Radiograph of the left foot. There is anatomic alignment of the tarsometatarsal (Lisfranc) joint with a screw connecting the first metatarsal and the medial cuneiform, and a screw connecting the second metatarsal and the medial cuneiform.

required to identify the injury correctly, as a patient may present symptoms consistent with sprains or other minor injuries. Treatment of severe cases may require open reduction and internal fixation followed by a period of immobilization. Complete recovery may take up to 1 year.

\section{Consent}

Written informed consent was obtained from the patient for publication of this case report and the accompanying images. A copy of the written consent is available for review by the Editor-in-Chief of this journal.

\section{Competing interests}

The authors declare that they have no competing interests.

\section{Authors' contributions}

$\mathrm{CB}$ wrote the first draft of the manuscript, obtained patient consent, and reviewed the literature. SP proofread the case report and provided revisions. All authors read and approved the final manuscript.

\section{References}

I. Sharma D, Khan F: Lisfranc fracture dislocations - An important and easily missed fracture in the emergency department. J R Army Med Corps 2002, I 48:44-47.

2. Sands A, Grose A: Lisfranc injuries. Injury 2004, 35:S-B7I-76.

3. Trevino $S$, Kodros $S$ : Controversies in tarsometatarsal injuries. Orthop Clin North Am 1995, 26:229-238.

4. Perron AD, Brady WJ, Keats TE: Orthopedic pitfalls in the ED: Lisfranc fracture-dislocation. Am J Emerg Med 200I, I 9:7I-75.

5. Haapamaki VV, Kluru MJ, Koskinen SK: Ankle and foot injuries: Analysis of MDCT findings. AJR 2004, I 83:6I5-622.

6. Nunley JA, Vertullo CJ: Classification, investigation, and management of midfoot sprains. Am J Sports Med 2002, 30:87I-878.

7. Lee CA, Birkedal JP, Dickerson EA, Vieta PA Jr, Webb LX, Teasdal RD: Stabilization of Lisfranc joint injuries: $A$ biomechanical study. Foot Ankle Int 2004, 25:365-370.

8. Rajapakse B, Edwards A, Hong T: A single surgeon's experience of treatment of Lisfranc joint injuries. Injury 2006, 37:9|4-92I.

9. Mulier T, Reynders P, Dereymaeker G, Broos P: Severe Lisfrancs injuries: primary arthrodesis or ORIF? Foot Ankle Int 2002, 23:902-905 Publish with Bio Med Central and every
scientist can read your work free of charge

"BioMed Central will be the most significant development for disseminating the results of biomedical research in our lifetime. "

Sir Paul Nurse, Cancer Research UK

Your research papers will be:

- available free of charge to the entire biomedical community

- peer reviewed and published immediately upon acceptance

- cited in PubMed and archived on PubMed Central

- yours - you keep the copyright
BioMedcentral 